\title{
FÁBULA E TRAMA
}

\section{Italo Caroni}

O presente trabalho visa a aplicar certos conceitos dos formalistas russos, sobretudo os de B. Tomachevski, à análise da obra Les Cloportes, do escritor francês Jules Renard.

Tomachevski adota, como ponto de partida para o estudo da elaboração artística, a distinção entre fábula e trama (1) Fábu a é o conjunto dos acontecimentos ligados entre si e transmitidos ao leitor no decurso da obra: pode ser exposta de maneira prática, segundo a ordem cronológica e causal dos acontecimentos. A trama (2) constitui o conjunto destes mesmos acontecimentos, porém, segundo a ordem em que aparecem na obra. A fábula, é, pois, o fato acontecido na realidade, e a trama o modo pe'o qual o leitor toma conhecimento deste fato. No primeiro caso, temos o acontecimento bruto, e, no segundo, elaboração do mesmo pelo artista. Partindo de uma simples nota polic.al, o escritor pode edificar uma construção complexa.

Esta distinção nos parece essencial quando se quer analisar do mesmo tempo a matéria do edifício e o modo pelo qual ela é disposta na sua arquitetura. Assim procedem os forma istas.

O estruturalismo admite, embora com ressalvas, a validade desta distinção básica. Todorov, por exemplo, partindo da oposição, estabelecida por Benveniste, entre discurso e história, ob;eta que toda palavra, literária ou não, implica ao mesmo tempo um depoimento sobre a realidade e um arranjo lingüístico da parte do locutor (3)

Toda palavra, e sobretudo a !iterária, poder-se-ia acrescentar $\mathrm{O}$ escritor não tem a liberdade de transformar o material lingüís-

(1). - B. Tomachevski, "Thématique", in THEORIE DE LA LITTERATURE, Textes des Formalistes russes. Paris, Seuil, 1965.

(2) - Fábula e Trama - (do francês "fable et sujet"): tradução adotada em As estruturas narrativas, p. 42. (Referência bibliográfica na nota 3, abaixo) e em Teoria da literatura, Formalistas russos, Pôrto Alegre, Ed. Globo, 1971, p. 172 e seguintes.

(3) - T Todorov, As estruturas narrativas, S. Paulo, Editôra Perspectiva, 1970, p. 59-61. 
tico, da mesma forma que o pintor não pode fazer com que a cor dexe de ser cor E da própria natureza da palavra que ela implique a existência das duas categorias acima, e o escritor não faz abstração delas. No fundo, todos nós somos, até certo ponto, escritores, visto que, na comunicação quotidiana mais banal, duas pessoas diferentes não elaboram o mesmo discurso linguístico para expressar a mesma rea idade. Mas, só é escritor aquele que consegue explorar ao máximo as possibilidades de arranjo da linguagem. Recaímos, portanto, na distinção inicial dos formalistas que, mesmo alheia às bases lingüísticas sobre as quais repousa, conserva toda a sua eficácia.

Uma outra objeção formulada por Todorov merece ser discutida. De acordo com ele, a oposição fábula e trama não corresponde a uma dicotomia entre a vida representada e o livre, mas sim à dupla natureza de enunciado e enunciação, imp ícita em toda palavra. Como estes dois últimos - enunciado e enunciação - a dupla fábula e trama dá vida a duas realidades puramente lingüísticas. Barthes diz a mesma coisa quando pretende que na narrativa nunca ocorre nada, e o que acontece é a linguagem apenas, "cuja" vinda nunca cessa de ser festejada" (4)

Entretanto, Tołorov, ao exemplificar a distinção lingüística de Benveniste, admite que a história remete a uma representação exterior, no caso da frase de Proust que ée cita, a de duas personagens e um ato. Quanto a Barthes, a procura de uma realidade superior enigmática, escondida atrás dos fatos evocados pela narrativa, não se concebe sem o pressuposto de que estes mesmos fatos sejam comunicados ao leitor pela linguagem.

Em outras palavras, a obra literária implica necessariamente a existência de um objeto exterior a partir do qual ela é elaborada e ao qual ela remete. Foi um dos formalistas, V Jirmunski, que, rebatendo os excessos dos próprios colegas - em particular os de Chkloviki - elucidou bem a questão, ao estabelecer uma classificação das artes em dois grupos: puras e temáticas.

Com efeito, para Jirmunsky (5), as artes puras - o ornamento, a música e a dança - utilizam um material estético abstrato, adaptado especialmente a fins artísticos e desprovidos de significado concreto, enquanto que as artes temáticas - pintura, escultura, poesia e teatro - empregam um material provido de signifi-

(4) - R. Barthes, "Introduction à l'analyse structurale du récit" Communications, Paris, 8 , p. 27

(5). - V Jirmunski, Sobre a questão do "Método Formal" In: Teoria de Literatura. Formalistas Russos, P Alegre, Editora Globo, 1971, p. 65-69. 
cação, concreto e ligado à vida prática. No caso da literatura, o material lingüístico não foi criado especialmente para finalidades artísticas, como, por exemplo, os tons musicais que são organizados inteiramente segundo princípios artísticos: a palavra serve antes de tudo à comunicação humana. Por isso, diz ele, "os sons providos de significação da fala humana, bem como as linhas de um retrato, executam uma tarefa temática definida; em consequiência disso, a composição de uma obra poética é determinada grandemente pela unidade de sentido, de substância, de objeto" (6)

Assim, sem negar a pertinência de estudos puramente formais, Jirmunski argumenta que a análise da obra literária só é completa quando se levam em conta também os temas: "O estudo da poesia do ponto de vista da arte exige atenção para o seu lado temático, para a própria escolha do tema, na mesma medida que para a sua estruturas ão, eläboração compositiva e combinação com outros temas" (7)

Cabe, portanto, ao escritor "executar", por meio da palavra, "uma tarefa temática" Em estado bruto, os vocábulos servem à comunicação, mas combinados segundo princípios artísticos, arquitetam um universo que o autor quer transmitir ao leitor. As combinações do material linguístico assumem as mais variadas formas que permanecem todas vá idas na medida em que não se desligam do objeto concreto que se propõem recriar. Em caso contrário, elas elaboram o que Tomachevski chama de obra transracional, sem sentido, mero exercício de laboratório para certas escolas poéticas (8)

Estabeleçamos, portanto, como postulado básico, que a obra literária é elaboração de um tema fornecido pela realidade concreta. Este tema, ou a soma de motivos que o compõem, se traduz pela noção formalista de fábula. Assim o entendem também Wellek e Warren quando afirmam que a fábula corresponde à matéria prima da obra e está 'igada à experiência ou às leituras do autor (9)

Posto isto, nosso objetivo é verificar como um escritor - Jules Renard - efetua a passagem da fábula, matéria bruta, à trama, obra artist camente elaborada. Tomaremos como ponto de referência uma obra que se situa no marco inicial da carreira literária de Renard: LES CLOPORTES.

Les Cloportes é o primeiro - e único - romance que Jules Renard escreveu observando uma estrita obediência às fórmulas do

(6). - V Jirmunski, Ib. p. 67

(7). - V Jirmunski, Ib. p. 67

(8). - B. Tomachevski, op. cit., p. 263.

(9). - R. Wellek, A. Warren, Teoría Literária, Madrid, Ed. Gredos, 1953, p. 381 . 
gênero. Embora preocupado scbretudo com a idéia de reproduzir o mundo e a mentalidade tacanha da vida interiorana de sua aldeia natal, o escritor não deixou de forjar uma intriga susceptível de aguçar o interesse do leitor, recorrendo para esse fim aos recursos habituais da narração romanesca.

Não é sem razão que os críticos da época se mostraram sensíve:s ao rigor com que o autor observou o emprego de tais recursos: "Au surplus, il en est encore à la rhétorique courante du livre 'construit', du récit progressivement mené, développé comme un drame, avec un sujet, une action, une conclusion, évoluant seulement avec une souplesse plus propice aux abandons de l'écrivain et aux fantais.es de l'artiste" (10)

"A retórica corrente do livro 'construído' transparece através da história de Françoise, a jovem empregada seduzida e abandonada a seu triste destino. Este fato, que poderia ter sido extraído da crônica policia! da época, constitui a fábula em torno da qual Renard estab lece toda a tessitura do romance. Reduzindo-o aos elementos estritamente necessários ao seu desenvolvimento cronológico e causal, temos: Françoise substituiu sua avó Honorine como empregada dos Lérin, cujo filho, Emile, volta de Paris. A jovem interessa-se por Emile que se mostra indiferente. $O$ interesse se transforma em amor, mas Emile continua a repeli-la. Um dia, o acaso faz com que os dois se encontrem no celeiro de feno e Emile a seduz. Grávida e aban Jonada, ela tudo faz para esconder seu estado. Porém, o dia fatal chega: ela dá à luz, sufoca a criança e joga-a no poço dos Lérin. Honorine apaga todos os traços do crime e ninguém percebe nada. Tomada de remorso, Françoise suicida-se. Honorine recupera o emprego junto aos Lérin, cuja vida continua como se nada tivesse acontecido.

Logo, a tragéd.a de Françoise teria sido perfeitamente clara, mesmo se o escritor se tivesse limitado a contá-la com, apenas, os vinte e quatro capítulos do resumo acima, a saber: V; XI; XII; XIII; XVI; XXIV; XXV; XXX; XXXI; XXXV; XXXVII e XXXVIII, da primeira parte; e, VI; VII; XX; XXI; XXII; XXV; XXVI; XXVII; XXIX; XXXI; XLIV e XLV, da segunda. No entanto, a obra acabada compreende nada menos que 84 capítulos, dimensão considerável, que se traduz, nas edições comuns, por um volume de 250 páginas.

O primeiro passo da abordagem de Tomachevski consiste em proceder à decomposição da obra total diante da qua' nos encontramos. O crítico cita o caso de $O$ tiro de pistola, de Pushkin, que

(10). - R. Marsy, L'Opinion, Paris, 9 septembre, 1919. 
se decompõe primeiro em duas narrativas distintas, as quais, por sua vez, se desdobram em duas outras. Entretanto, $O$ tiro de pistola é uma novela $\mathrm{e}$, infelizmente, se os estudos formalistas tratam com frequiência deste gênero, são mais discretos no que se refere ao romance. Mesmo o trabalho de $\mathrm{V}$ Chklovski sobre a construção da novela e do romance (11) fornece mais indicações no que diz respeito à primeira. Dos processos por ele ana isados - construção em patamares, construção circular, paralelismo, "enfilage" (12) -, apenas o primeiro é deduzido da forma romanesca; e, mesmo assim, trata-se do romance de aventuras que, até certo ponto, não se afasta do esquema da novela.

Talvez nos seja mais esclarecedor o contraste estabelecido por B. Eikhenbaum entre estas duas variedades da literatura narrativa (13) Para este teórico, a novela se caracteriza pela construção baseada numa contradição, e tende, com impetuosidade, para a conclusão; o romance, pelo contrário, utiliza uma técnica que visa a diminuir a velocidade de ação, desenvolver e ligar episódios, criar centros de interesses diferentes, conduzir intrigas paralelas. E isso o que the permite - depois de afirmar ainda que a construção romanesca exige que o desfecho seja um momento de enfraquecimento e não de reforço - terminar o confronto com esta imagem bastante sugestiva: "On comparera le roman à une longue promenade à travers des lieux différents, qui suppose un retour tranquille; la nouvelle à l'escalade d'une colline, ayant pour but de nous offrir la vue qui se découvre depuis cette hauteur" (14)

Nada define melhor a impressão que nos deixa um romance do t po de Les Cloportes que esta imagem de um longo passeio por lugares d.ferentes, com um retôrno tranqüilo. O ritmo lento, a diversidade de centros de interesse, as intrigas pare'elas e o epílogo

(11) - V. Chklovski, "La construction de la nouvelle et du roman." In: Théorie de la littérature. Formalistes russes, p. 170-196.

(12). - A tradução destes termos, tal qual foi feita em Teoria da Literatura, Formalistas russos, $\mathrm{P}$ Alegre, 1970, deixa a desejar:

- Construção em plataformas sucessivas (em francês: "en paliers sucessifs"): a rigor, poder-se-ia traduzir palier por plataforma, mas parece importante conservar em português a noção de movimento ascensional, implicada na forma de construção a que alude Chklovski, e que encontramos de preferência no termo patamares.

- Composição picaresca (em francês: "composition par 'enfilage'") A palavra picaresco ou picaresca tem o inconveniente de remeter a um gênero de narrativa por demais conhecido; seria mais interessante adotar o termo "enfiámento" e, como na solução francesa, encaixá-lo, por enquanto, entre aspas.

(13) - B. Eikhenbaum, "Sur la Théorie de la prose" Théorie de

(14) - B. Eikhenbaum, Ibid., p. 203-204. 
em forma de balanço final, tudo contribui para confirmar o acerto da sugestão de Eikhenbaum.

Assim, enquanto a novela tende a concentrar a ação, o romance procura dispersá-la. Se uma visa à unidade, o outro parte para a diversidade. Disso decorre o háb.to bastante freqüente de o romancista acumular detalhes e situações. Hábito que nos permitiria, talvez, levantar como hipótese a possibilidade de muitos romances repousarem sobre um tipo de construção por justaposição.

No caso de Les Cloportes, a idéia parece válida, dado que a própria divisão da obra em duas partes não desempenha outro papel senão o de somar dois conteúdos cuja natureza é praticamente a mesma: dois aspectos de um mesmo ambiente - o provinciano -; duas faces de um único drama - o destino de Françoise. Quanto à recriação do universo aldeão de Titly, o esquema da justapos.ção é indiscutível: as duas metades do romance são perfeitamente simétricas, sendo que a segunda retoma. para desenvolvê-los de novo, tópicos da primeira, centralizadas em torno da evocação de costumes camponeses. No que se refere à vida de Françoise,a adaptação ao referido esquema demanda explicações complementares: à primeira vista, tem-se a impressão de que narrativa se assenta antes sobre um princípio coordenador, viso que o tema geral da primeira parte - sedução - parece complementar-se pelo da segunda - crime (Françoise, mata a criança porque foi seduzida por Emile) Mas, o verdadeiro drama da jovem não é tanto a sedução quanto o abandono de que é vítima. O que dá unidade ao seu destino é a solidão; e, neste sentido, a estrutura dupla do romance imp ica em repetir uma mesma situação que se reduz à fórmula: Françoise ama Emile, Emile não ama Françoise.

Renard poderia ter parado o romance no desfecho da primeira parte. Se concebeu uma segunda foi para reforçar a ilustração de um mesmo tema.

Prosseguindo na tarefa de decomposição que consiste, segundo Tomachevski, em isolar as partes caracterizadas por uma unidade temática específica, podemos definir os centros de interesse que constituem núcleos menores que os das duas grandes partes de Les Cloporte.

Também aqui é possível discernir várias simetrias no processo de elaboração renardiana. Distinguem-se no desenvolvimento desta cbra várias unidades temáticas que são, do geral para o particular, a natureza, a aldeia, a famíia e as personagens isoladas. Limitar-nos 
-emos, para cada caso, a assinalar grandes analogias de procedimento nas duas partes.

A natureza permite a Jules Renard "rechear" seu romance de numerosos "close-ups", que aparecem aqui e ali, mas destaca-se no conjunto da obra a simetria mais evidente entre a longa descrição do capítulo final da primeira parte - (Oeuvres, t. 1, pp. 159-161) e os capítulos XXXI e XXXV. da segunda (pp. 200-207) No que se refere à vida da família Lérin, convém destacar sobretudo VI; VII; VIII e IV; V e XLIV (pp. 166-169 e 219-220) Os usos e costumes da aldeia de Tit'y esbəçam-se de maneira precisa no vaivém constante dos capítulos I; XXII; XXV e I; II; VII; XXXIX-XLII (pp. 83-88; 133-140 e 162-164; 170-172; 210215) No domínio das personagens, a correspondência é ainda mais minuciosa, mas basta sublinhá-la com relação àquelas que desempenham um papel mais importante. O caráter de Françoise e Emile bem como a natureza dos sentimentos que experimentam um pelo outro se traduzem na repetição de fragmentos mais ou menos equivalentes nas duas partes: IV-V; IX-XIII; XVI; XXVII-XXXV; XXXVII-XXXIX e II-III; VI; VIII; XV; XVIII-XXIII; XXVI; XXXIII; XXXV; XXXVII; XLIII-XLV (pp. 94-101; 106-108; $112-115 ; 118-120 ; 141-152 ; 157-161$ e $163-166$; 169-170; 172173 ; 184-185; 187-192; 195-196; 199-200; 203-205; 206-207; 208-209; 215-221) Duas intrigas paralelas são esboçadas na primeira parte e reaparecem, sem modificação, na segunda: o interesse frustrado do carteiro Fabrice por Françoise - XIX; XXXIV e XIII-XIV; XVI-XVII (pp. 125, 150-151 e 181-183; 186-187) -, e o malogro dos pretendentes à mão de Eugénie - XXVI e V (pp. 153-157 e 168-169)

Quanto aos fragmentos temáticos referidos, a segunda parte do romance nada mais faz que retomar trechos da primeira, desenvolvendo-os outra vez, sem jamais alterá-los. Assim, da mesma forma que no caso da divisão da obra em duas faces iguais, o corte das unidades temáticas demonstra a existência de um modelo de construção por jusaposição. Este processo de organizar a narrativa corresponde ao intuito primeiro de escritor, que era transpor no plano literário a atmosfera monótona e rotineira da vida provinciana na cidadezinha de Tit'y Por este motivo parece-nos justa a apreciação de León Guichard, que, procurando mostrar os méritos do incipiente romancista Jules Renard, afirma: "Et la stagnation des premiers chapitres, la lenteur mise par Renard à nouer l'intrigue et, le crime commis, à la dénouer me semblent répondre pleinement à l'intention de l'auteur: montrer l'étouffante mon^tonie de cette vie 
réglée une fois pour toutes, que rien - même le crime - ne peut déranger, où tout finalement s'eng'outira dans le silence" (15)

Vemos, portanto, como toda uma técnica se torna tributária da vontade de organização que preside o trabalho do artista. Les Cloportes se desenrola em ritmo de câmara lenta porque o escritor tem necessidade de se estender na pintura de uma atmosfera. O que importa não são tanto os atos das personagens, mas antes a descrição do ambiente que os amolece e lhes tira toda vontade de agir. No fundo, muito pouca coisa acontece ao longo dos 84 capítulos.

As personagens vegetam e o seu comportamento é fruto da força coercitiva do ambiente. Os dois fatos centrais - sedução e crime - explicam-se por injunção das circunstâncias e jamais por decisão dos heróis: Françoise e Emile fazem amor porque o acaso os reúne num celeiro onde o contacto macio e morno do feno os excita (pp. 143-147); depois do parto, Françoise sufoca a criança porque as condições terríveis em que dá à luz provocam sua completa alienação, física e moral, e seu gesto é inconsciente (pp. 188192)

Sugestão de uma certa tonalidade, como queria Flaubert, esboço não de um caráter mas de um temperamento, segundo pregava Zola, assim aparecem as diretivas que orientam a criação romanesca do jovem Renard. Ambas parecem adaptar-se ao esquema da justaposição por nós sugerido mas que por enquanto, também não vai além da hipótese.

A decomposição da obra literária, iniciada pela divisão em narrativas e prosseguida pelo corte em unidades temáticas, tem um ponto final na menor unidade, que Tomachevski chama motivo. Parte indecomponível da estrutura narrativa, o motivo se define como a menor unidade de sentido. Cada proposição, diz o formalista russo, possui seu próprio motivo.

Aqui, deve-se reconhecer que o estruturalismo, aproveitando as pesquisas formalistas, vai mais longe, e as aprimora. Barthes admite, como Tomachevski, que o sentido deve ser o critério da unidade. E, ao tomar este postulado como ponto de partida, não deixa de lembrar a dívida do estruturalismo para com os formalistas, sobretudo Tomachevski e Propp, assim como não esquece de salientar as contribu ções com que um Todorov e um Greimas procuram aperfeiçoar o legado daque es (16)

(15). - J . Renard, Oeuvres, I, p. 78.

(16). - R. Barthes, "Introduction à l'analyse structurale du récit" Communications, 8, p. 6 e rota 2 . 
Barthes discorda, porém, de Tomachevski quando se trata de identificar a un.dade lingüística que corresponde ao motivo indecomponível. Enquanto o formalista pára na proposição, o estruturalista segue adiante, sustentando que as primeiras unidades narrativas não coincidem, nem com as formas tradicionais das partes do discurso narrativo - ações, cenas, parágrafos, diálogos, monólogos _, nem tampouco com as unidades linguísticas.

Todorov formula, com um raciocínio diverso, a mesma restrição. Com a prudência que sempre o caracteriza, recomenda ao pesquisador o cuidado de não identificar motivo e oração, que pertencem a séries nocionais diferentes. Por outro lado, invocando um exemplo de Propp citado igualmente por Barthes, conc ui que a frase pode conter mais de um motivo, ou inversamente (17)

A ressalva dos estruturalistas se justifica plenamente e mostra o limite da posição tomachevskiana, que se impõe quando consideramos um exemplo, tomado a uma passagem de Les Cloportes, e válido como qualquer outro: "Il en venait aussi d'un peu partout. Les élus posaient 'eurs sabots en entrant, prévenus par Pierre que c'etait une façon de montreor sa bonne éducation et de ne pas se conduire comme de petits libertins" (p. 86) É fácil constatar que uma proposição como esta compreende, "grosso modo", duas unidades temáticas, sendo que a primeira vai até entrant e corresponde ao motivo introdutório das crianças que vêm à casa dos Lérin pedir boas festas, ao passo que a segunda remete ao motivo de caracterização de Pierre, e começa a partir de prévenus.

A classificação dos motivos proposta por Tomachevski se revela, mais uma vez, capaz de guiar nossos passos.

Um primeiro grupo compreende os motivos associados e os motivo livres. Associados são aque'es que não podem ser excluídos sem que seja alterado o elo que une os acontecimentos; livres, aqueles cuia supressão não prejudica a sucessão crono ógica e causal dos acontecimentos. Os primeiros têm importância para a fábula, os outros para a trama.

Consideramos, em Les Cloportes, o fragmento formado pelos capítulos XXXI a XXXVII, da segunda parte (pp. 200-209) Começando pela descrição do passeio de Françoise e o irmãozinho Pierre, pelo bosque, eles culminam com a morte da jovem na fogueira que o garoto acendera para brincar. Todo o trecho implica a existência do motivo suicídio, que é indispensável ao desenrolar da fábu a - logo, motivo associado. Entretanto, Renard elaborouo lentamente, concebendo uma série de episódios nos quais obtém,

(17). - T Todorov, Estruturas Narrativas, p. 36. 
pelo contraste entre o desejo que o menino tem de distrair Françoise e a tristeza irremediável da irmã, uma intensificaçãò do efe to dramático. Efeito coroado pela morte de Françoise como uma santa consumida pelo fogo (p. 209) O autor poderia ter descrito o suicídio de outra forma, sem que isso alterasse a fábula sobre a qual se apóia o romance. Os motivos utilizados seriam outros, portanto livres. Se Renard os escolheu como tais foi porque os julgou adequados aos princípios que presidem à e'aboração de Les Cioportes. Os motivos livres obedecem, por conseguinte, à visão romanesca do autor.

A distinção entre estas duas categorias de motivos denota, tanto quanto as inversões temporais - sobre as quais vo'taremos a insistir mais adiante - a intervenção do autor na narrativa. Além do mais, constitui, conforme se depreende das considerações de Tomachevski, um valioso instrumento para o pesquisador que queira determinar a filiação de um escritor a uma "escola" literária, pois cada uma destas possui um repertório de motivos livres que lhe são inerentes.

Vários críticos tentaram justamente, sem dificuldades, aliás, seguir as pistas que denunciam a inspiração naturalista imprimida por Renard à Les Cloportes. Marcel Politzer chama a atenção para o desfecho melodramático da história de Françoise (18) Segundo André Beaunier, tal orientação se manifesta, sobretudo, pelo tratamento de certos temas bem ao gosto do Naturalismo, como: cenas de luxúria, parto, infanticídio, suicídio (19) E indiscutível que estes temas, por estarem intimamente ligados à fábula do romance, pertencem à categoria dos motivos associados, mas o que os torna típicos de uma tendência literária é a maneira como são tratados, isto é, o conjunto de motivos livres que os revestem.

Antes de chegar a um segundo grupo de motivos - estáticos e dinâmicos - Tomachevski precisa o conceito de situação, que está na origem deste novo desmembramento. A situação típica é constituída pelas re ações conflitantes das personagens num dado momento e tende a ser modificada por essas personagens. Deste ponto de vista, motivos dinâmicos são os que a modificam, e estáticos, os inoperantes contra ela. Entre os primeiros, incluem-se os feitos do herói; as descrições da natureza, do lugar, da situação das personagens e dos caracteres fazem parte da segunda categoria.

(18). - M. Pollitzer, Jules Renard: sa vie, son oeuvre, Paris, Editons du Vieux Colombier, 1956, p. 50.

(19) - A. Beaunier, Le premier livre de Jules Renard, Revue des Deux Mondes, Paris, 54, 1919, p. 687 
O procedimento artístico de Renard em Les Cloportes assume grande nitidez quando encarado de acordo com estas duas variedades de motivos. Constata-se, então, que os estáticos superam os dinâmicos. Os protagonistas parecem desprovidos de vontade própria e, uma vez desenhada a situação que os opõe, esboçam raros gestos para mudá-la: Franço.se procura Emile com moderado entusiasmo, e o jovem, sem nunca se decidir claramente, limita-se a evitar as ocasiões que o levariam a agir. Esta situação (A procura $\mathrm{B}, \mathrm{B}$ evita A), delineada já no capítulo IX, da primeira parte (p. 207) perdura, excetuada a breve pausa de reconci iação forçada (p. 120), até a chamada cena de luxúria, onde o conflito desaparece, mas, como vimos, por obra do acaso (pp. 146-147)

Em compensação, o escritor con centra todo o esforço na evocação do cenário em que se desenrola a ação. Quase todo o espaço da narrativa é preenchido pela descrição de paisagens naturais, da aldeia de Titly, da casa dos Lérin e da dos Fré, e, enfim, pela caracterização, ao mesmo tempo física e moral, das numerosas personagens. Sente-se, com frequiência, a preocupação do jovem romanc.sta em exercer o talento na captação de uma determinada realidade. A trama supera a fábula.

Como primeiro indício desta característica do romance, destaca-se a preferência de Renard pelos motivos livres e estáticos, em prejuízo dos associados e dinâmicos. Mas, no âmbito da elaboração destes últimos, patenteia-se igualmente o desejo de acentuar a trama, como podemos verificar ao seguir unicamente o desenvolvimento da ação.

Levando-se em conta o esquema de justaposição decorrente da construção total da obra, devemos considerar Les Cloportes como dois blocos independentes, concretizados por duas grandes divisões. A exposição ou, como afirma Tomachevski, a narração das circunstâncias que determinam o estado inicial das personagens e as suas relações, é dupla, compreendendo os capítulos I a IX da primeira parte (pp. 83-108) e I a VI, da segunda (pp. 162-169) Nos dois casos, e'a tem por função introduzir o leitor no universo de Titly e na vida dos Lérin.

Renard recorre de início à forma mais simples, ou seja, à exposição direta. As duas exposições centralizam-se na descrição dos costumes provincianos e na apresentação dos protagonistas. Tudo someça num dia primeiro de ano, e o romance fornece indícios suficientes para se provar que se trata de 1887 Entretanto, os fatos narrados a propósito deste dia inscrevem-se na monotonia eterna na 
qual se entorpecem não só os Lérin, mas toda Titly. Para comunicar esta impressão ao leitor, o romancista se vê obrigado a ut.lizar a técnica do retrocesso e da exposição retardada.

$\mathrm{Na}$ primeira parte, os capítulos II; III; IV; VI; VII; e VIII, relatando a vida passada de, respectivamente, Honorine, Fabrice, Emi e, e do casal Lérin, remonta a uma data que se situa, pelo menos, a dez anos antes do início da ação (p. 89) O mesmo acontece no capítulo III, da segunda parte (p. 164), quando Françoise, para esquecer o seu triste estado atual, rememora os bons tempos da infância e os sonhos de adolescente.

Posteriormente, na sequiência dos acontecimentos expostos na introdução, o autor interrompe a narrativa, para voltar de novo a eventos que precedem aquele primeiro de ano. Assim ressurgem, detalhes do passado de Emile. dona Suzanne, Eugénie ( $1^{\mathrm{a}}$ parte, pp. 132-133; 133-134; 153-157) e Honor ne (2a parte, p. 179180) Desta feita, trata-se de exposição retardada que vem completar as informações fornecidas sobre a personagem na introdução e no decorrer da narrativa.

Este processo de retorno da narração sobre si mesma aplica-se à introdução tanto quanto a qualquer outra parte da obra. O capítulo XVII, da primeira parte ( $p$ p. 121-123), constitui uma pausa que suspende o curso dos acontecimentos, para se vo tar à estaca zero, ao dia primeiro, e a partir daí assistir-se ao que sucedeu com Honorine enquanto o narrador contava a vida das outras personagens. Caso mais típico ainda se registra na segunda parte, a propósito da mesma personagem: cronologicamente, o capítulo XXIV se situaria antes do XXIII (pp. 192-194) Há outros exemplos, menos importantes, porém i'ustrativos da mesma técnica: $1 .^{\mathrm{a}}$ parte, cap. XXXIII (pp. 148-149), 2. ${ }^{\mathrm{a}}$ Farte, cap. XXXIX (pp. 210211)

O conjunto dos motivos que caracterizam o desenvolvimento da ação formam a intriga. Para Tomachevski, ela compreende essencialmente a luta entre as personagens cujos interesses são contra ditórios. Vimos como, no tocante ao dado central do romance a aventura amorosa de Françoise e Emile -, as peripécias são escassas. Contudo, elas existem. Convém lembrar sob:etudo o papel de Honorine, sempre vigilante e pronta, apesar das modestas possibilidades, a intervir em favor da neta. Isto a leva várias vezes a entrar em conflito com Madame Lérin, protetora do filho indolente e covarde. Diversas situações traduzem este choque: $1 .^{\mathrm{a}}$ parte, cap. XVII (p. 120); 2. ${ }^{\text {a }}$ parte, cap. XXVII (pp. 196-197); cap. XLIV (Fp. 219-220) —, mas seu ponto culminante é a cena em 
que a velha empregada, imbuída de uma pálida esperança, pede à austera Madame Lérn que obrigue Emile a esposar Françoise $\left(2 .^{\mathrm{a}}\right.$ farte, cap. IX, pp. 173-178) Nesta cena, uma das mais 'ongas do romance, o autor procura, visivelmente, obter um forte efeito dramático. A disputa entre as duas contedoras, não obstante a desigualdade de forças, assume contornos vio entos.

Uma das intrigas paralelas a que já aludimos - Fabrice e Françoise -, além de sub.inhar o amor da moça por Emile, tem por função dramatizar os acontecimentos. O velho carteiro, depois de propor inutilmente casamento a Françoise, acaba por irritar-se e tenta violentá-la (2. ${ }^{\mathrm{a}}$ parte. cap. XIII-XIV pp. 181-183) As reações de Françoise, durante a briga, levam-no a compreender que ela está g-ávida de Emile. A partir de então, nas três cenas subsequientes, a narração evolui de modo a criar suspense: Emile, de espingarda na mão, mantém-se imóvel, à espreita da caça, enquanto Fabrice, segurando a foice com que cortava mato, aproxima-se, lentamente, por trás: quando a tragédia está prestes a estourar, uma ave cai, atingida pelo tiro de Emile e os dois homens conversam, em seguida amigavelmente sobre a destreza do caçador (pp. 184-187)

Temos, neste episódio, uma amostra flagrante do arranjo que combina habilmente os motivos, de maneira a produzir um efeito preconcebido. Como nos demais exemplos citados, o autor manipula a intriga com o intuito de aumentar a tensão dramática, que é um dos ingredentes habituais do romance minuciosamente construído.

Quanto ao desfecho de Les Cloportes, deve-se dizer que aí se evidencia menos a elaboração artística do auter Isto se explica talvez pela natureza do gânero romanesco, que, como assinala Eikhenbaum (20), exige, na conclusão, um epílogo ou falso desfecho equivalente a um balanço final. Tomachevski, por suas vez, lembra o caso do desfecho regressivo. isto é, daquele que contém elementos capazes de esclarecer as peripécias expostas desde o início da narrativa. Entretanto, este expediente parece mais adaptado ao gênero policial. Les Cloportes, embora relatando uma história que leva ao crime, nada tem de romance policial. Mas Renard não deixa de explorar. discretamente é verdade, uma variedade do desfecho regressivo: nos quatro capítu os consagrados ao enterro de Françoise (pp. 210-215), transcreve a conversa das velhas Suzanne e Ledru, e assim emergem detalhes alusivos a fatos decorridos anteriormente $\mathrm{e}$ ignorados pelo leitor Merece destaque a referência feita por dona Suzanne a uma conversa que tivera com Françoise (p. 210), pro-

(20). - B. Eikhenbaum, "Sur la théorie de la prose" In: Théorie de la Littérature, p. 203. 
vavelmente na noite do parto (p. 188): as palavras da jovem empregada, reportadas agora, revelam sua intenção de suicidar-se.

Resumindo esta análise do romance, podemos afirmar que, tanto pela predominância de motivos livres e estáticos, quanto pelas combinaçōes da trama no seu trip'o aspecto de exposição, intriga t desfecho, Les Cloportes se define como uma obra arquitetada segundo as receitas do gênero romanesco.

Para um escritor como Jules Renard, tão obcecado pela preocupação com a verdade, este primeiro aprovisionamento no arsenal dos artifícios de um gênero deformador da realidade não poderia, de forma alguma, repetir-se. Ele reconheceu de imediato que se enganara de caminho, e pôs-se em busca de um tipo de narrativa que satisfizesse mais suas exigências artísticas. O crítico Henri Bachelin inclui no prefácio à primeira edição das obras completas de Renard um depoimento no qual o escritor declara, a propósito dos camponeses que 'he forneceram um vasto material artístico: "Sur eux, jaurais pu écrire des nouvelles, des romans, même, cela ne m'intéresse plus. Nouvelle et roman déforment la vie. Rien ne me choque plus qu'un retour en arrière, qu'une intrigue inventée de toutes pièces. Ce qu'il faut, c'est la peinture, qui donne l'illusion de la photographie" (21)

Os retrocessos e as intrigas forjadas, que utilizou largamente em Les Cloportes, aparecem-lhe então como defeitos e não qualidades. $\mathrm{Da}$ mesma forma que a aventura episódica com a qual f'oreia a morte de Françoise, episódio que pretendia suprimir, como atesta o Journal (22) Diversas outras referências desse diário explicitam esta repugância crescente pela narração romanesca (27) Gostaríamos de lembrar apenas uma, por ser das mais significativas: "Je ne vois dans la vie que des raisons de ne pas écrire un roman" (23)

Eis por que, depois da experiência de Les Cloportes, Renard condenou definitivamente este gênero literário, pelo menos, na forma ritual em que era praticalo. Já a partir de L'Ecornifleur notase uma evolução sensível, cujo término será Ragotte, a mais longa das narrativas de Nos frères farouches.

(21). - Débuts littéraires, p. LV

(22) - Journal, p. 33.

(23) - Journal, p. 845 . 